\title{
Characteristics of MR Infarcts Associated with Dementia and Cognitive Function in the Elderly
}

\author{
Neelum T. Aggarwal ${ }^{a} \quad$ Julie A. Schneider ${ }^{a}$ Robert S. Wilson ${ }^{a}$ Todd L. Beck ${ }^{a}$ \\ Denis A. Evans ${ }^{a}$ Charles De Carlib \\ ${ }^{a}$ Rush University Medical Center, Chicago, Ill., and b University of California at Davis, Sacramento, Calif., USA
}

\section{Key Words}

Stroke $\cdot$ Dementia $\cdot$ Cognitive function $\cdot$ Biracial population sample $\cdot$ Magnetic resonance imaging

\begin{abstract}
Background: Little information exists on the simultaneous effects of magnetic resonance (MR) infarct characteristics, that may increase the likelihood of dementia or lower cognitive function in community populations. Methods: Participants were 580 community-dwelling individuals from the Chicago Health and Aging Project (CHAP) who underwent detailed clinical evaluation and MR imaging. The association of MR infarct characteristics (region, number, side, and size) with dementia, global cognition and cognition in five separate cognitive domains was examined using logistic and linear regression analyses controlling for age, sex, race, education and time elapsed between clinical evaluation and MRI. Results: A total of 156 persons had MR infarcts: 108 with 1 infarct and 48 with multiple. Poorer cognitive function and, in particular, slower perceptual speed, were associated with infarcts characterized as cortical, multiple, bilateral or large (all $p<0.05$ ). Multiple infarcts in multiple regions were associated with poor performance in all cognitive domains except visuospatial ability $(p<0.05)$. Race did not modify any of these associations. Conclusions: In this community sam-
\end{abstract}

ple, cortical and multiple infarcts in multiple regions were associated with dementia; cortical, multiple, large and bilateral infarcts were associated with lower cognition, particularly lower memory function and perceptual speed. These effects were not modified by race.

Copyright $\odot 2011$ S. Karger AG, Basel

\section{Introduction}

Cerebral infarcts noted in magnetic resonance imaging (MRI; 'infarcts' herein) are common in the elderly. Several studies found that infarcts are related to dementia and lower cognitive function [1-7], though others did not $[8,9]$, and some also found that infarcts are associated with lower scores on specific cognitive tests, but not on others [10-12]. Few studies have systematically examined the association of infarcts with dementia and cognitive function in a large cohort of older persons based on specific infarct characteristics such as number, size, side, and region $[2,4,5]$. The combination of various infarct traits may be a stronger predictor of dementia and cognitive impairment than any single infarct characteristic alone. Thus, clarifying the effects of these infarct combinations could improve our understanding of the underlying mechanisms of cognitive impairment and potentially aid

\section{KARGER \\ Fax +4161306 1234 E-Mail karger@karger.ch} www.karger.com

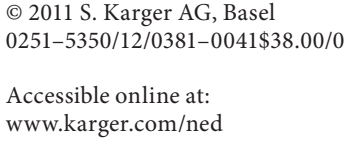

Neelum T. Aggarwal, MD

Rush Alzheimer's Disease Center

600 South Paulina Avenue, Suite 1038

Chicago, IL 60612 (USA)

Tel. +1 312942 2338, E-Mail Neelum_T_Aggarwal@rush.edu 
in ascertaining the relative risk of impairment should these combinations exist in routine neuroimaging scans. To examine these questions, we used data from the Chicago Health and Aging Project (CHAP), an ongoing epidemiological study of aging and Alzheimer's disease (AD), to examine specific infarct characteristics and their association with dementia and cognitive function in a biracial sample of more than 500 older individuals. We then examined whether any of these associations varied by race/ethnicity.

\section{Methods and Materials}

\section{Study Population}

CHAP is a longitudinal population study on common chronic health problems in black and white older adults. Beginning in $1993,78.7 \%$ of residents over 65 years old in a geographically defined, biracial Chicago community were enrolled in the study. Each data collection cycle has two in-home phases: a population interview with brief physical and cognitive function tests, and a clinical evaluation of a stratified random sample of subjects. Clinical evaluations were conducted by a team of examiners led by a senior neurologist, with structured neurological evaluations and medical histories carried out by trained nurse clinicians. A senior neuropsychologist, blinded to age, gender, race, and clinical data other than the subject educational level, occupation, and information about sensory or motor deficits, reviewed the results of 17 cognitive performance tests and summarized impairment in five areas (orientation, attention, memory, language, and perception). Participants were evaluated in person by a neurologist or geriatrician with expertise in evaluating older persons with and without dementia. Based on this evaluation, participants were classified with respect to $\mathrm{AD}$ and other common conditions with the potential to impact cognitive function. Details of the evaluation have previously been described $[13,14]$. Dementia diagnosis required assessment of loss of cognitive function and impairment in two or more areas of cognitive performance testing. AD diagnosis used the National Institute of Neurological and Communicative Disorders and Stroke-Alzheimer's Disease and Related Disorders Association (NINCDS-ADRDA) criteria [15], and vascular dementia diagnosis used NINCDS-AIREN criteria [16]. Clinical stroke diagnosis was based on a review of the participant's medical history and a neurological exam [17, 18].

Of the 1,242 subjects completing the clinical evaluation, 580 persons participated in an MRI evaluation. They had a mean age of 79.8 years $(\mathrm{SD}=5.9)$, completed a mean of 13.0 years of education $(\mathrm{SD}=3.7)$, and had a mean Mini Mental State Examination (MMSE) score of $26.2(\mathrm{SD}=3.8) ; 57.1 \%(331 / 580)$ were women and $58.3 \%(338 / 580)$ were African American. Dementia was present in 81 (14\%) participants: $75 \mathrm{AD}$ dementia cases, 2 cases of vascular dementia, 3 cases of dementia of unknown subtype and 1 case of Parkinson's disease. We repeated our analyses excluding the 2 persons with vascular dementia because vascular dementia may remain static and show no progression over time. Results were comparable to the full dementia group; thus, all results reported in this article were performed with the full dementia group. Signed informed consent was obtained from each subject, and the Institutional Review Board of Rush University Medical Center approved the study.

Cognitive Assessment. The 17 cognitive function tests assessed a broad range of cognitive abilities that may be differentially affected by aging and $\mathrm{AD}$, and included measures of episodic memory [19-21], semantic memory [22, 23], working memory [24], perceptual speed $[25,26]$, and visuospatial ability $[27,28]$. The MMSE was used for descriptive purposes only. We constructed summary measures of global cognition and each of the five cognitive domains into which we hypothesized the test could be grouped (episodic memory, semantic memory, working memory, perceptual speed, and visuospatial ability), rather than using individual test scores. Each summary measure was constructed by converting the raw scores from individual tests to $\mathrm{z}$ scores using the mean and SD from the baseline clinical evaluation of all participants in the CHAP study and averaging the $\mathrm{z}$ scores. Valid summary measures required valid scores on at least half of the component tests. Several studies characterizing cognitive function using this approach and other cohorts have previously been reported [29-33].

\section{MRI Evaluation}

The methods for MRI acquisition and infarct quantification were previously described [34]. Subjects were imaged on a General Electric 1.5-T scanner (Excite platform, version 11), and the following imaging sequences were obtained: FLAIR: TR $=11,000$, TE 144, T1 2,250, 22-cm FOV, 3-mm slide thickness, $192 \times 256$ acquisition matrix; APGR: TE minimum, 20-degree flip angle, 24-cm FOV, $1.5-\mathrm{mm}$ slice thickness with $256 \times 256$ acquisition matrix, and Double spin Echo: TR $=2,100, \mathrm{TE}=30 / 92,22-\mathrm{cm}$ FOV, 4-mm slice thickness, with $256 \times 192$ acquisition matrix. Digital information was then transferred to a central laboratory for processing and analysis. Analyses were performed blind to any identifying information and used the Quanta 6.2 package. Lesions $3 \mathrm{~mm}$ or larger were considered brain infarcts. Infarct number, region (cortical, subcortical), side, and size $(<1 \mathrm{~cm}, \geq 1 \mathrm{~cm})$ were also recorded. Two raters determined the presence of cerebral infarcts on MRI. Previously published kappa values for agreement among raters have been good, ranging from 0.73 to 0.90 [34].

\section{Statistical Analysis}

Differences between groups with and without infarcts were compared using t tests (continuous variables) or $\chi^{2}$ tests (categorical variables).

Multiple logistic regression models were used to document association of MR infarct characteristics with the presence of dementia, controlling for age, sex, education, race, and time from clinical evaluation to MRI. We determined the odds of dementia in those with infarcts and conducted similar analyses using the number, size, laterality, and region of infarcts as predictors. Numbers of infarcts were coded as dummy variables, representing none, one, or more than one infarct. For all analyses, the referent group was MRI participants with no infarcts. To examine the combined effects of infarct number and region, infarcts were further classified into the following groups: (1) none; (2) single infarct; (3) multiple infarcts $(>1)$ in the same region (i.e., cortical, subcortical, or brainstem/cerebellar), and (4) multiple infarcts in 
Table 1. Characteristics of cohort based on infarct status

\begin{tabular}{llll}
\hline & $\begin{array}{l}\text { No infarct } \\
(\mathrm{n}=424)\end{array}$ & $\begin{array}{l}\text { Infarct(s) } \\
(\mathrm{n}=156)\end{array}$ & $\begin{array}{l}\mathrm{p} \\
\text { value }\end{array}$ \\
\hline Age, years & $79.4 \pm 5.5$ & $80.8 \pm 5.3$ & 0.01 \\
Sex (female) & $42.2 \%$ & $44.2 \%$ & 0.70 \\
Race (African American) & $60.0 \%$ & $53.2 \%$ & 0.14 \\
Education, years & $13.1 \pm 3.4$ & $12.6 \pm 3.5$ & 0.17 \\
MMSE score (/30) & $26.4 \pm 3.6$ & $25.9 \pm 4.3$ & 0.34 \\
\hline
\end{tabular}

Values are mean $\pm \mathrm{SD}$ or percent.

two or more regions. We included terms for those with small $(<1$ $\mathrm{cm})$, large $(\geq 1 \mathrm{~cm})$, and both small and large MR infarcts compared to the reference group. In the model examining infarct laterality, we included terms for left-, right-, and both left- and rightsided infarcts. We used multiple logistic models with cortical infarcts, subcortical infarcts, and brainstem/cerebellar infarcts (each compared to no brainstem/cerebellar infarcts) as predictors in the same model; this accounts for persons with infarcts in all three regions.

A similar set of regression models examined the association of infarct characteristics with the global measure of cognitive function and with each summary measure of the five cognitive domain groups. We investigated whether these associations varied by race/ethnicity using interaction terms. All models were validated graphically and analytically. Statistical significance was determined at $\mathrm{p}<0.05$. All analyses were performed using SAS/ STAT software version 9.2 [35].

\section{Results}

\section{Description of the Cohort Based on Infarct Status}

MRI scans of 156 persons (26.9\%) showed evidence of one or more infarcts. Persons with infarcts and those without did not differ significantly with respect to sex, race, education, or mean MMSE score; however, persons with infarcts were slightly older (80.8 vs. 79.4 , table 1 ). Approximately $72 \%$ of subjects with MRI infarcts had no evidence of stroke via history or exam (10 in the cortical group, 100 in the subcortical group, 2 in the cortical and subcortical group, and 9 in the brainstem/cerebellar group).

Of the persons with infarcts, $16(10.3 \%)$ had cortical (2 with multiple), 122 (78.2\%) had subcortical, 5 (3.2\%) had both cortical and subcortical, and 13 (8.3\%) had brainstem/cerebellar (table 2). One hundred and eight persons (18.6\%) had evidence of one infarct, while 48 (8.3\%) had more than one (30 persons with 2, 9 with 3, 4 with 4,4 with 5 , and 1 with 7 ).

MR Infarcts Associated with Dementia and Cognitive Function
Table 2. Region, number, size and side of cerebral infarcts ${ }^{\mathrm{a}}$

\begin{tabular}{lccl}
\hline & $\begin{array}{l}\text { Cortical } \\
\text { only }\end{array}$ & $\begin{array}{l}\text { Subcor- } \\
\text { tical only }\end{array}$ & $\begin{array}{l}\text { Both cortical } \\
\text { and subcortical }\end{array}$ \\
\hline Number with infarct present & 16 & 122 & 5 \\
\hline $\begin{array}{l}\text { Number in each category } \\
\text { Number }\end{array}$ & & & \\
$\quad$ One infarct & 14 & 90 & 0 \\
$\quad 2$ & 32 & 5 \\
$\quad$ Two or more & 1 & 107 & 0 \\
$\quad$ Small $(<1 \mathrm{~cm})$ & 13 & 5 & 0 \\
$\quad$ Large $(\geq 1 \mathrm{~cm})$ & 2 & 10 & 5 \\
$\quad$ Small and large & 6 & 37 & 1 \\
Side & 8 & 63 & 2 \\
$\quad$ Left & 2 & 22 & 2 \\
$\quad$ Right & & & \\
$\quad$ Left and right & &
\end{tabular}

${ }^{a}$ Not included in table, 13 persons with brainstem/cerebellar infarcts.

Table 3. Cerebral infarcts and odds of dementia ${ }^{\mathrm{a}}$

\begin{tabular}{lll}
\hline Cerebral infarcts and dementia & OR $(\mathrm{CI})$ dementia & p value \\
\hline $\begin{array}{l}\text { Presence of infarcts } \\
\text { Number of infarcts }\end{array}$ & $1.10(0.64-1.88)$ & 0.730 \\
$\quad$ One & $0.85(0.44-1.63)$ & 0.617 \\
$\quad$ Two or more & $1.80(0.82-3.95)$ & 0.140 \\
Size & & \\
$\quad$ Small $(<1.0 \mathrm{~cm})$ & $0.82(0.44-1.53)$ & 0.535 \\
$\quad$ Large $(\geq 1.0 \mathrm{~cm})$ & $2.41(0.88-6.76)$ & 0.096 \\
$\quad$ Large and small & $2.78(0.94-8.25)$ & 0.063 \\
Region & & \\
$\quad$ Cortical & $4.79(1.81-12.75)$ & 0.002 \\
$\quad$ Subcortical & $0.87(0.49-1.57)$ & 0.648 \\
$\quad$ Brainstem/cerebellar & $2.31(0.84-6.35)$ & 0.104 \\
Side & & \\
$\quad$ Left & $0.73(0.29-1.84)$ & 0.499 \\
$\quad$ Right & $1.20(0.60-2.38)$ & 0.607 \\
$\quad$ Left and right & $1.55(0.63-3.79)$ & 0.339 \\
\hline
\end{tabular}

a Logistic regression models controlling for age, sex, education, race, and elapsed time from clinical evaluation to MRI; reference group with no cerebral infarcts.

\section{Infarcts and Dementia}

Persons with cortical infarcts were more than fourfold more likely to have dementia. By contrast, the odds of dementia in persons with subcortical infarcts were 0.87 . Persons with one infarct did not have increased odds of 
Table 4. Cerebral infarcts and cognitive domain scores ${ }^{\mathrm{a}}$

\begin{tabular}{|c|c|c|c|c|c|c|}
\hline & \multicolumn{6}{|c|}{ Parameter estimates for cognitive domain scores ( $\mathrm{p}$ values) } \\
\hline & $\begin{array}{l}\text { global } \\
\text { cognition }\end{array}$ & $\begin{array}{l}\text { episodic } \\
\text { memory }\end{array}$ & $\begin{array}{l}\text { semantic } \\
\text { memory }\end{array}$ & $\begin{array}{l}\text { working } \\
\text { memory }\end{array}$ & $\begin{array}{l}\text { perceptual } \\
\text { speed }\end{array}$ & $\begin{array}{l}\text { visuospatial } \\
\text { ability }\end{array}$ \\
\hline \multicolumn{7}{|l|}{ Number } \\
\hline One & $0.043(0.366)$ & $0.104(0.080)$ & $0.040(0.054)$ & $0.019(0.759)$ & $0.042(0.570)$ & $-0.051(0.427)$ \\
\hline Two or more & $-0.215(0.002)$ & $-0.238(0.005)$ & $-0.179(0.035)$ & $-0.204(0.025)$ & $-0.375(0.001)$ & $-0.123(0.180)$ \\
\hline \multicolumn{7}{|l|}{ Size } \\
\hline Small $(<1.0 \mathrm{~cm})$ & $-0.007(0.881)$ & $0.011(0.852)$ & $-0.013(0.822)$ & $-0.028(0.635)$ & $-0.57(0.423)$ & $-0.051(0.392)$ \\
\hline Large $(\geq 1.0 \mathrm{~cm})$ & $-0.201(0.041)$ & $-0.124(0.320)$ & $-0.188(0.120)$ & $-0.304(0.020)$ & $-0.429(0.006)$ & $-0.253(0.052)$ \\
\hline Large and small & $-0.061(0.549)$ & $-0.010(0.940)$ & $0.020(0.876)$ & $-0.085(0.529)$ & $-0.361(0.021)$ & $-0.001(0.991)$ \\
\hline \multicolumn{7}{|l|}{ Side } \\
\hline Left & $0.042(0.522)$ & $0.041(0.617)$ & $0.056(0.485)$ & $0.016(0.850)$ & $0.053(0.608)$ & $0.001(0.993)$ \\
\hline Right & $-0.003(0.958)$ & $0.053(0.436)$ & $-0.015(0.820)$ & $-0.031(0.660)$ & $-0.163(0.057)$ & $-0.135(0.063)$ \\
\hline Left and right & $-0.217(0.005)$ & $-0.214(0.029)$ & $-0.193(0.046)$ & $-0.258(0.011)$ & $-0.350(0.004)$ & $-0.026(0.797)$ \\
\hline \multicolumn{7}{|l|}{ Region } \\
\hline Cortical & $-0.278(0.005)$ & $-0.016(0.202)$ & $-0.150(0.222)$ & $-0.445(<0.001)$ & $-0.549(<0.001)$ & $-0.216(0.105)$ \\
\hline Subcortical & $-0.015(0.788)$ & $-0.001(0.981)$ & $0.014(0.795)$ & $-0.051(0.372)$ & $-0.053(0.431)$ & $-0.050(0.384)$ \\
\hline Brainstem/cerebellar & $-0.099(0.309)$ & $-0.104(0.397)$ & $-0.280(0.019)$ & $0.059(0.646)$ & $-0.306(0.041)$ & $0.054(0.683)$ \\
\hline
\end{tabular}

${ }^{a}$ Linear regression models controlling for age, sex, education, race, and elapsed time from clinical evaluation to MRI.

Table 5. Infarct number and region and cognitive performance ${ }^{a}$

\begin{tabular}{|c|c|c|c|c|c|c|c|}
\hline & \multicolumn{7}{|c|}{ Parameter estimate for cognitive domain scores, standard errors ( $\mathrm{p}$ value) } \\
\hline & $\begin{array}{l}\mathrm{n} \text { in each } \\
\text { category }\end{array}$ & $\begin{array}{l}\text { global } \\
\text { cognition }\end{array}$ & $\begin{array}{l}\text { episodic } \\
\text { memory }\end{array}$ & $\begin{array}{l}\text { semantic } \\
\text { memory }\end{array}$ & $\begin{array}{l}\text { working } \\
\text { memory }\end{array}$ & $\begin{array}{l}\text { perceptual } \\
\text { speed }\end{array}$ & $\begin{array}{l}\text { visuospatial } \\
\text { ability }\end{array}$ \\
\hline No infarct & 424 & reference & reference & reference & reference & reference & reference \\
\hline One infarct/one region & 108 & $\begin{array}{l}0.044,0.047 \\
(0.357)\end{array}$ & $\begin{array}{l}0.104,0.060 \\
(0.083)\end{array}$ & $\begin{array}{l}0.041,0.059 \\
(0.494)\end{array}$ & $\begin{array}{l}-0.019,0.063 \\
(0.768)\end{array}$ & $\begin{array}{l}-0.041,0.075 \\
(0.586)\end{array}$ & $\begin{array}{c}-0.051,0.064 \\
(0.422)\end{array}$ \\
\hline Two or more/single region & 34 & $\begin{array}{l}-0.157,0.079 \\
(0.047)\end{array}$ & $\begin{array}{l}-0.194,0.099 \\
(0.051)\end{array}$ & $\begin{array}{l}-0.105,0.099 \\
(0.288)\end{array}$ & $\begin{array}{l}-0.152,0.105 \\
(0.150)\end{array}$ & $\begin{array}{l}-0.284,0.125 \\
(0.023)\end{array}$ & $\begin{array}{c}-0.170,0.107 \\
(0.112)\end{array}$ \\
\hline Two or more/multiple regions & 14 & $\begin{array}{l}-0.364,0.123 \\
(0.003)\end{array}$ & $\begin{array}{l}-0.353,0.155 \\
(0.024)\end{array}$ & $\begin{array}{c}-0.362,0.153 \\
(0.018)\end{array}$ & $\begin{array}{c}-0.336,0.165 \\
(0.041)\end{array}$ & $\begin{array}{c}-0.590,0.188 \\
(0.002)\end{array}$ & $\begin{array}{c}-0.005,0.165 \\
(0.975)\end{array}$ \\
\hline
\end{tabular}

${ }^{a}$ Linear regression models controlling for age, sex, education, race, and elapsed time from clinical evaluation to MRI.

having dementia (table 3). The odds of dementia with multiple infarcts were 1.80 (not statistically significant). In further analyses, persons with multiple infarcts in multiple regions had sixfold increased odds of dementia, whereas those with multiple infarcts in a single region did not differ significantly from persons with no infarcts (data not shown). There were no associations with the anatomical aspect of infarcts (table 3 ). We added an interaction term for race/ethnicity to all of our models; no interactions were noted.

\section{Cerebral Infarcts and Global Cognition}

In a multiple linear regression model with cortical, subcortical, and brainstem/cerebellar infarcts, only cortical infarcts were significantly associated with poor global cognition (table 4). Multiple infarcts were associated with poorer global cognition, but a single infarct was not. Infarcts in multiple rather than single regions were associated with poorer global cognitive function (table 5). Bilateral infarcts were associated with poor global cognitive function but had no association with a specific side. 
Large infarcts were associated with poorer global cognition, whereas smaller infarcts were not (table 4). Similarly, no interactions were noted when we added a term for race/ethnicity.

\section{Cerebral Infarcts and Cognitive Systems}

We next examined if associations of infarcts varied across the five cognitive domains (table 4). As expected, MR infarct characteristics were most consistently and strongly related to perceptual speed. Cortical infarcts were strongly associated with poorer performance in perceptual speed and working memory. Moreover, multiple infarcts lowered episodic memory, a cognitive system most closely associated with $\mathrm{AD}$ (tables 4, 5). Bilateral infarcts were associated with poorer performance in all cognitive systems except visuospatial ability. Large infarcts were associated with poorer working memory and perceptual speed. We added terms for the interaction between race/ethnicity. Of 25 separate models, only two had interactions, about the expected number by chance, providing little evidence that race/ethnicity modified the examined association.

Because the combination of infarct number and region may be a stronger predictor of cognitive function than infarct number or infarct region alone [36], we examined the relationship between multiple infarcts and multiple regions and cognitive performance. Participants with multiple infarcts in multiple regions had poorer performance in our global measure of cognitive function than those with multiple infarcts in a single region, and exhibited poorer performance in all but one cognitive system (table 5).

\section{Discussion}

In this study, we found that several MR infarct characteristics were important to cognitive function: cortical infarcts and multiple infarcts in multiple regions were associated with increased odds of dementia. Cortical, multiple, or large infarcts were associated with lower global cognitive function (particularly lower perceptual speed) and memory function. Finally, the effect of MR infarcts on dementia and cognitive function did not vary by race or ethnicity.

Over the last decade, several clinical radiological studies have shown that cerebral infarcts noted on MRI increase the odds of dementia and these associations may depend on specific infarct characteristics such as number $[3,37,38]$, size, side $[4,7,39]$, or region $[2,40]$. However, whether these associations are similar in the general population is largely unknown. Only two previous studies have examined this issue $[3,37]$. The first study [3] found that the presence of one or more large infarcts noted on MRI was associated with increased risk of dementia. Other infarct characteristics, such as location or anatomical side, were not examined. In the second study [37], infarcts were present in $21 \%$ of the sample and were characterized based on their presence or absence, anatomical location, and size. The presence of infarcts noted in the baseline evaluation more than doubled the risk of having dementia and was associated with poor global cognitive performance. The results of this current study suggest that infarcts are associated with an increased risk of dementia and lowered cognitive function but also extend these findings in several important ways.

We found that cortical infarcts and multiple infarcts in multiple regions increased the odds of having dementia. Cortical infarcts are more likely to impair cognitive function due to their large size and the involvement of multiple areas of gray matter $[4,7,8,39,41]$. In contrast to findings from clinical pathological studies that have shown that persons with lacunar infarcts (typically subcortical) were more likely to have dementia, or needed fewer plaques and tangles for a clinical diagnosis of $\mathrm{AD}$ [42-45], we did not find an association between subcortical infarcts and odds of dementia or lowered cognitive function. Several factors could account for the discrepancies in results. A significant proportion of the sample was not demented, which may have limited the amount of coexisting $\mathrm{AD}$ pathology. Second, there was overlap between persons with cortical and subcortical infarcts. For instance, in our sample, only 32 of the 122 persons with subcortical infarcts had two or more infarcts, and only 10 of the 122 persons had small and large infarcts. Small numbers in some groups may have limited the ability to detect an association, making interpretation difficult.

The presence and region of additional infarcts may also have influenced the effect of subcortical infarcts. As reported by others [11,37], multiple infarcts from multiple regions were linked to an increase in dementia and lowered cognitive function. This may suggest that not all subcortical infarcts are deleterious, but that a subgroup of persons with subcortical infarcts and with infarcts specifically in the cortex, brainstem, or cerebellum is susceptible to dementia and lowered cognitive function. Indeed, this may reflect more widespread and severe vascular disease. Whether these and other factors play a role in the association of subcortical infarcts (and cortical infarcts) 
with dementia will need to be explored in further studies with larger numbers.

Although infarcts were associated with lower function in a spectrum of cognitive domains, perceptual speed had the strongest and most consistent association with infarcts - a finding consistent with several clinical radiologic study results [46-48]. Disruption of the prefrontal-subcortical loops may be involved, which can lead to impaired prefrontal lobe functioning and impaired information processing $[49,50]$. Infarcts have also been associated with poor performance in episodic, semantic, and working memory, consistent with previous studies, suggesting that though the pattern and severity of cognitive impairment may differ, infarcts can mimic and compound some of the primary effects of AD pathology [51, 52].

Although studies have suggested that cerebrovascular disease and cerebral infarcts are more prevalent among African Americans [53-57] and may play a larger role in the etiology of dementia within this racial group, in our sample, the association of infarcts with risk of dementia and lower cognitive function was similar among African Americans and Caucasians, suggesting that race/ethnicity alone does not modify the association of infarcts with cognitive function. Longitudinal assessment of cognitive function in relation to infarcts is needed to further examine these preliminary observations.
This study's strengths include a large well-characterized cohort of older blacks and whites, inclusion of dementia and continuous measures of global cognitive function, and specific cognitive systems in our analytic models. We conducted analyses with multiple cerebral infarct characteristics. When we explored combined characteristics, the group numbers decreased; thus, further study with larger sample sizes is necessary. Other limitations include the cross-sectional design and losses for MRI participation. In addition, the association of infarcts with other neuroimaging and biological markers relevant to dementia and cognitive function (e.g. white matter hyperintensities, hippocampus, infarct lesion volumes, and vascular factors) was not assessed and requires future study.

\section{Acknowledgments}

We thank Ann Marie Lane for community development and oversight of the project coordination; Michelle Bos, Jennifer Tarpey, and Colleen Plunkett for coordination of the study, and Deborah Holub and Sandra Horowitz, MD, for the coordination of the neuroimaging evaluation.

This study was supported by grant AG11101 from the National Institute on Aging, Bethesda, Md., USA.

\section{References}

1 Pohjasvaara T, Erkinjuntti T, Ylikoski R, Hietanen M, Vataja R, Kaste M: Clinical determinants of poststroke dementia. Stroke 1998;29:75-81.

$\checkmark 2$ Pohjasvaara T, Mantyla R, Salonen O, Aronen HJ, Ylikoski R, Hietanen M, Kaste M, Erkinjuntti T: How complex interactions of ischemic brain infarcts, white matter lesions, and atrophy relate to poststroke dementia. Arch Neurol 2000;57:1295-1300.

$\checkmark 3$ Kuller LH, Lopez OL, Newman A, Beauchamp NJ, Burke G, Dulberg C, Fitzpatrick A, Fried L, Haan MN: Risk factors for dementia in the cardiovascular health cognition study. Neuroepidemiology 2003;22:13-22.

-4 Pohjasvaara T, Mantyla R, Salonen O, Aronen HJ, Ylikoski R, Hietanen M, Kaste M, Erkinjuntti T: MRI correlates of dementia after first clinical ischemic stroke. J Neurol Sci 2000;181:111-117.

5 Kuller LH, Lopez OL, Jagust WJ, Becker JT, DeKosky ST, Lyketsos C, Kawas C, Breitner JC, Fitzpatrick A, Dulberg C: Determinants of vascular dementia in the Cardiovascular Health Cognition Study. Neurology 2005;64: 1548-1552.
6 Desmond DW, Moroney JT, Paik MC, Sano M, Mohr JP, Aboumatar S, Tseng CL, Chan S, Williams JB, Remien RH, Hauser WA, Stern Y: Frequency and clinical determinants of dementia after ischemic stroke. Neurology 2000;54:1124-1131.

-7 Tatemichi TK, Desmond DW, Paik M, Figueroa M, Gropen TI, Stern Y, Sano M, Remien R, Williams JB, Mohr JP, et al: Clinical determinants of dementia related to stroke. Ann Neurol 1993;33:568-575.

8 Sachdev PS, Brodaty H, Valenzuela MJ, Lorentz L, Looi JC, Berman K, Ross A, Wen W, Zagami AS: Clinical determinants of dementia and mild cognitive impairment following ischaemic stroke: the Sydney Stroke Study. Dement Geriatr Cogn Disord 2006;21: 275-283.

-9 Mungas D, Jagust WJ, Reed BR, Kramer JH, Weiner MW, Schuff N, Norman D, Mack WJ, Willis L, Chui HC: MRI predictors of cognition in subcortical ischemic vascular disease and Alzheimer's disease. Neurology 2001;57: 2229-2235.

-10 Longstreth WT Jr, Dulberg C, Manolio TA, Lewis MR, Beauchamp NJ Jr, O’Leary D,
Carr J, Furberg CD: Incidence, manifestations, and predictors of brain infarcts defined by serial cranial magnetic resonance imaging in the elderly: the Cardiovascular Health Study. Stroke 2002;33:2376-2382.

11 Prins ND, van Dijk EJ, den Heijer T, Vermeer SE, Jolles J, Koudstaal PJ, Hofman A, Breteler MM: Cerebral small-vessel disease and decline in information processing speed, executive function and memory. Brain 2005; 128 : 2034-2041.

12 Nyenhuis DL, Gorelick PB: Vascular dementia: a contemporary review of epidemiology, diagnosis, prevention, and treatment. J Am Geriatr Soc 1998;46:1437-1448.

13 Bienias JL, Beckett LA, Bennett DA, Wilson RS, Evans DA: Design of the Chicago Health and Aging Project (CHAP). J Alzheimers Dis 2003;5:349-355.

14 Evans DA, Bennett DA, Wilson RS, Bienias JL, Morris MC, Scherr PA, Hebert LE, Aggarwal N, Beckett LA, Joglekar R, Berry-Kravis $\mathrm{E}$, Schneider J: Incidence of Alzheimer disease in a biracial urban community: relation to apolipoprotein E allele status. Arch Neurol 2003;60:185-189. 
-15 McKhann G, Drachman D, Folstein M, Katzman R, Price D, Stadlan EM: Clinical diagnosis of Alzheimer's disease: report of the NINCDS-ADRDA Work Group under the auspices of Department of Health and Human Services Task Force on Alzheimer's Disease. Neurology 1984;34:939-944.

16 Roman GD, Tatemichi TTK: Report on the NINCDS International Workshop. Neurology 1993;43:250-260.

$\checkmark 17$ Goldstein LB: Interrater reliability of the NIH Stroke Scale. Arch Neurol 1989;46: 660-662.

18 Foulkes MA, Wolf PH, Price TR: The Stroke Data Bank: design, methods, and baseline characteristics. Stroke 1988;19:547-554.

-19 Morris JC, Heyman A, Mohs RC, Hughes JP, van Belle G, Fillenbaum G, Mellits ED, Clark C: The Consortium to Establish a Registry for Alzheimer's Disease (CERAD). Part I. Clinical and neuropsychological assessment of Alzheimer's disease. Neurology 1989;39: 1159-1165.

-20 Albert M, Smith LA, Scherr PA, Taylor JO, Evans DA, Funkenstein HH: Use of brief cognitive tests to identify individuals in the community with clinically diagnosed Alzheimer's disease. Int J Neurosci 1991;57:167178 .

21 Wechsler Memory Scale-Revised: Manual. New York, Psychological Corporation, 1987.

22 Kaplan E, Goodglass H, Weintraub S: The Boston Naming Test. Philadelphia, Lea \& Febiger, 1983.

23 Nelsen HE: National Adult Reading Test (NART) test manual. Windsor, NFER-Nelson Publishing Company, 1982.

-24 Cooper JA, Sagar HJ: Incidental and intentional recall in Parkinson's disease: an account based on diminished attentional resources. J Clin Exp Neuropsychol 1993;15: 713-731.

25 Ekstrom RB, French JQW, Harman H, Dermen D: Manual for kit of factor-referenced cognitive tests. Princeton, Educational Testing Service 1976.

26 Smith A: Symbol Digit Modalities Test Manual-Revised. Los Angeles, Western Psychological, 1984.

-27 Benton AL, Varney NR, Hamsher KD: Visuospatial judgment: a clinical test. Arch Neurol 1978;35:364-367.

28 Raven JC, Court JH, Raven J: Standard progressive matrices; in Raven Manual, Oxford, Oxford Psychologists Press, 1992.

-29 Wilson RS, Bienias JL, Evans DA, Bennett DA: Religious Orders Study: overview and change in cognitive and motor speed. Aging Neuropsychol Cogn 2004;11:280-303.

-30 Bennett DA, Schneider JA, Buchman AS, Mendes de Leon C, Bienias JL, Wilson RS: The Rush Memory and Aging Project: study design and baseline characteristics of the study cohort. Neuroepidemiology 2005;25: 163-175.
1 Wilson RS, Aggarwal NT, Barnes LL, Bienias JL, Mendes de Leon C, Evans DA: Biracial Population Study of Mortality in Mild Cognitive Impairment and AD. Arch Neurol 2009;66:667-672.

32 Rand WM: Objective criteria for the evaluation of clustering methods. J Am Statist Assoc $1971 ; 66: 847-850$.

33 Wilson RS, Aggarwal NT, Barnes LL, Mendes de Leon C, Hebert LE, Evans D: A cognitive decline in incident Alzheimer disease in a community population. Neurology 2010;74:951-955.

34 DeCarli C, Massaro J, Harvey D, Hald J, Tullberg M, Au R, Beiser A, D’Agostino R, Wolf PA: Measures of brain morphology and infarction in the Framingham Heart Study: establishing what is normal. Neurobiol Aging 2005;26:491-510.

35 Allison PD: Survival Analysis Using the SAS System: A Practical Guide. Cary, SAS Institute Inc., 1995.

36 Saczynski JS, Sigurdsson S, Jonsdottir MK, Eiriksdottir G, Jonsson PV, Garcia ME, Kjartansson O, Lopez O, Van Buchem MA, Gudnason V, Launer LJ: Cerebral infarcts and cognitive performance: importance of location and number of infarcts. Stroke 2009;40: 677-682.

37 Vermeer SE, Longstreth WT Jr, Koudstaal PJ Silent brain infarcts: a systematic review. Lancet Neurol 2007;6:611-619.

38 Tomlinson BE, Blessed G, Roth M: Observations on the brains of demented old people. J Neurol Sci 1970;11:205-242.

39 Knopman DS, Parisi JE, Boeve BF, Cha RH, Apaydin H, Salviati A, Edland SD, Rocca WA: Vascular dementia in a populationbased autopsy study. Arch Neurol 2003;60: 569-575.

40 Tatemichi TK, Desmond DW, Prohovnik I: Strategic infarcts in vascular dementia. A clinical and brain imaging experience. Arzneimittelforschung 1995;45:371-385.

-41 Pohjasvaara T, Mantyla R, Aronen HJ, Leskela M, Salonen O, Kaste M, Erkinjuntti $\mathrm{T}$ : Clinical and radiological determinants of prestroke cognitive decline in a stroke cohort. J Neurol Neurosurg Psychiatry 1999;67: 742-748.

42 Snowdon DA, Greiner LH, Mortimer JA, Riley KP, Greiner PA, Markesbery WR: Brain infarction and the clinical expression of Alzheimer disease. The Nun Study. JAMA 1997;277:813-817.

-43 Schneider JA, Wilson RS, Cochran EJ, Bienias JL, Arnold SE, Evans DA, Bennett DA Relation of cerebral infarctions to dementia and cognitive function in older persons. Neurology 2003;60:1082-1088.

44 Jellinger KA, Seppi K, Wenning GK, Poewe W: Impact of coexistent Alzheimer pathology on the natural history of Parkinson's disease. J Neural Transm 2002;109:329-339.
45 Jellinger KA, Mitter-Ferstl E: The impact of cerebrovascular lesions in Alzheimer disease - a comparative autopsy study. J Neurol 2003;250:1050-1055.

46 Kramer JH, Reed BR, Mungas D, Weiner MW, Chui HC: Executive dysfunction in subcortical ischaemic vascular disease. J Neurol Neurosurg Psychiatry 2002;72:217-220.

47 Price TR, Manolio TA, Kronmal RA, Kittner SJ, Yue NC, Robbins J, Anton-Culver H, O'Leary DH: Silent brain infarction on magnetic resonance imaging and neurological abnormalities in community-dwelling older adults. The Cardiovascular Health Study. CHS Collaborative Research Group. Stroke 1997;28:1158-1164

48 Bowler JV, Hachinski V, Steenhuis R, Lee D: Vascular cognitive impairment: clinical, neuropsychological, and imaging findings in early vascular dementia. Lancet 1998; 352(suppl 4):63.

49 Cummings JL: Frontal-subcortical circuits and human behavior. Arch Neurol 1993;50: 873-880.

50 Roman GC, Erkinjuntti T, Wallin A, Pantoni L, Chui HC: Subcortical ischaemic vascular dementia. Lancet Neurol 2002;1:426-436.

-51 Schneider JA, Arvanitakis Z, Bang W, Bennett DA: Mixed brain pathologies account for most dementia cases in communitydwelling older persons. Neurology 2007;69: 2197-2204.

52 Schneider JA, Arvanitakis Z, Leurgans SE, Bennett DA: The neuropathology of probable Alzheimer disease and mild cognitive impairment. Ann Neurol 2009;66:200-208.

53 Lopez OL, Jagust WJ, Dulberg C, Becker JT, DeKosky ST, Fitzpatrick A, Breitner J, Lyketsos C, Jones B, Kawas C, Carlson M, Kuller LH: Risk factors for mild cognitive impairment in the Cardiovascular Health Study Cognition Study: part 2. Arch Neurol 2003; 60:1394-1399.

54 Gurland BJ, Wilder DE, Lantigua R, Stern Y, Chen J, Killeffer EH, Mayeux R: Rates of dementia in three ethnoracial groups. Int J Geriatr Psychiatry 1999;14:481-493.

$\checkmark 55$ White H, Boden-Albala B, Wang C, Elkind MS, Rundek T, Wright CB, Sacco RL: Ischemic stroke subtype incidence among whites, blacks, and Hispanics: the Northern Manhattan Study. Circulation 2005;111: 1327-1331.

56 Brickman AM, Schupf N, Manly JJ, Luchsinger JA, Andrews H, Tang MX, Reitz C, Small SA, Mayeux R, DeCarli C, Brown TR: Brain morphology in older African Americans, Caribbean Hispanics, and Whites from northern Manhattan. Arch Neurol 2008;65:1053-1061.

57 Bryan RN, Cai J, Burke G, Hutchinson RG, Liao D, Toole JF, Dagher AP, Cooper L: Prevalence and anatomic characteristics of infarct-like lesions on MR images of middleaged adults: the atherosclerosis risk in communities study. AJNR Am J Neuroradiol 1999;20:1273-1280. 